ORIGINAL ARTICLE

\title{
Job constraints and arterial hypertension: different effects in men and women: the IHPAF \| case control study
}

\author{
S Radi, T Lang, V Lauwers-Cancès, E Diène, G Chatellier, L Larabi, R De Gaudemaris for the IHPAF \\ group
}

See end of article for authors' affiliations

Correspondence to:

Professor T Lang,

Département

d'Epidémiologie et de Santé Publique, Unité INSERM 558, Faculté de Médecine, 37, Allées Jules Guesde, 31073 Toulouse Cedex, France; lang@cict.fr

Accepted 10 May 2005

\begin{abstract}
Aims: To examine, in a working population of men and women, the relation between organisational job constraints (job strain, passive and active jobs) and incident hypertension and the buffering effect of social support at work on this relation.

Methods: A nested case control study was designed within the IHPAF (Incidence of Hypertension in a French Working Population) cohort study. The 20 worksite physicians participating in the study enrolled 203 cases and matched each case for age (SD 10 years) and sex with two normotensive subjects attending the follow up screening immediately after him or her. As a result, 426 men and 183 women were included in the study.

Results: Mean age was 41.8 (SD 7.8) years in men and 43.5 (SD 7.5) years in women. Relations between job constraints and hypertension were stronger in women than in men. Odds ratios (OR) were $3.20195 \%$ $\mathrm{Cl} 0.92$ to 11.12$)$ in women and $2.60(95 \% \mathrm{Cl} 1.15$ to 5.85$)$ in men for job strain, $4.73(95 \% \mathrm{Cl} 1.36$ to $16.42)$ in women and $2.30(95 \% \mathrm{Cl} 1.01$ to 5.26$)$ in men for passive jobs, and $4.51(95 \% \mathrm{Cl} 1.24$ to 16.43 ) in women and $2.39(95 \% \mathrm{Cl} 1.10$ to 5.18$)$ in men for active jobs. Low social support at work was not related to hypertension and did not decrease the association with organisational risk factors. In both hypertensive men and women, obesity was related to hypertension $(O R=13.20(95 \% \mathrm{Cl} 3.34$ to 52.14$)$ in women and 6.54 (95\% Cl 2.99 to 14.29) in men) and the prevalence of recent stressful life events was significantly lower in hypertensive women $(O R=0.32(95 \% \mathrm{Cl} 0.12$ to 0.89$)$ ) and men $(\mathrm{OR}=0.37(95 \% \mathrm{Cl}$ 0.20 to 0.67$)$ compared with normotensives. Alcohol consumption was a significant risk factor for hypertension in women (OR $=3.47(95 \% \mathrm{Cl} 1.18$ to 10.25$))$.

Conclusion: A stronger relation between job constraints and hypertension was observed in women compared with men. These findings emphasise the need of addressing more sex-specific concepts of work related stress on the one hand, and of understanding the direct and indirect mechanisms linking psychosocial factors and hypertension in both sexes on the other hand.
\end{abstract}

$\mathrm{P}$ ychosocial constraints at the workplace have increased due to changes in work organisation during the last two decades. ${ }^{1}$ Occupational stressors have been identified as one source of life stress, which can influence blood pressure levels. ${ }^{2}{ }^{3}$ Different models have been proposed to measure stressful working conditions. The Karasek model emphasises the effects of psychological demand and job control. This model has two assumptions. It first postulates that job strain, the combination of high psychological demand and low decision latitude, may result in a high level of stress. Job strain is supposed to be related to the more health adverse outcomes compared with the low strain group, which combines low psychological demand and high decision latitude. The second assumption is that active work situations are assumed to be associated with more autonomy and less stress reactions, the stressful condition of high psychological demand being limited by a high control over work. $^{45}$ Conversely, in passive jobs, high demand is not compensated by control over work. This situation can trigger stress responses. Social support at work, added to the model later has been suggested to have a direct effect and also to buffer the negative effect of low control and high demand. ${ }^{6}$

A large body of evidence has supported the link between job strain and cardiovascular disease. ${ }^{78}$ Ambulatory blood pressure levels have been shown to increase in work situations with high job strain, either directly ${ }^{9}$ or through behaviours modification, ${ }^{10}{ }^{11}$ and contribute ultimately to the development of cardiovascular disease. ${ }^{12}$ However, few studies have reported the relation between job strain and casual blood pressure, particularly in women. Fewer studies have assessed the role of social support in the relation between job strain and hypertension. ${ }^{13}{ }^{14}$

The aims of our study were to analyse in a working population of men and women (1) the relation between incident arterial hypertension and organisational occupational risk factors, and (2) to examine whether social support buffers the effects of these risk factors on hypertension.

\section{METHODS}

\section{Population and design}

The study is a case control study nested in the IHPAF (Incidence of Hypertension in a French Working Population) cohort study. This latter has been described in detail. ${ }^{15-17}$ Briefly, the cohort study was designed to assess the one-year incidence of hypertension in a working population. Forty eight worksite physicians selected on a voluntary basis and representative of national occupational activities enrolled randomly 25754 working subjects during the mandatory annual examination (baseline screening). Workers were included in the cohort study only if they could be screened at the following annual examination (that is, if they would be employed in the same job at least one year from the baseline screening). Among these 25754 workers, 20781 (17 909

Abbreviations: BMI, body mass index; IHPAF, Incidence of Hypertension in a French Working Population 
normotensive subjects at baseline and 2872 prevalent hypertensive subjects) were surveyed at the following mandatory annual examination (follow up screening). Among the 17909 normotensive workers at baseline, 1412 were hypertensive (incident cases) and 16497 were normotensive (controls) at follow up.

The conditions for the workers' inclusion in the case control study was that their working conditions: (1) had been stable for one year, between the baseline and the follow up screenings, and (2) would be assessed before the moment the workers learned about their blood pressure status. The inclusion in the case control study was based on a voluntary basis for occupational physicians and participants. Twenty volunteers among the 48 worksite physicians who had participated in the cohort study agreed to participate in a nested cross sectional case control study during the one year follow up screening. They enrolled 203 cases on the 1.412 incident hypertensives. Incident hypertensive participants $(n=203)$ and non-participants in the case control study $(n=1209)$ were compared for age, occupational category, educational level, and behaviour. In men, lack of sports activity prevalence was lower in hypertensive participants than in non-participants $(54.2 \% \quad v 63.0 \%, \mathrm{p}=0.04)$. In women, smoking prevalence was higher in hypertensive participants than in non-participants $(34.4 \% \quad v \quad 19.7 \%$, $\mathrm{p}=0.01$ ). Each incident case was matched for age (SD 10 years) with two normotensive workers attending the screening immediately after him or her (controls). Each worker agreeing to participate in the study gave informed consent.

Occupational physicians collected at baseline data on age, occupation, educational level, and marital status by standardised interviews. Medical examinations were performed at baseline and follow up during working hours either at the worksite or at the physician's office. To standardise blood pressure measurements, all worksite physicians participated in a training session. Sitting blood pressure was measured with a validated automatic device (OMRON 705CP) ${ }^{18}$ and an appropriate cuff size after 5, 6, and 7 minutes of rest. The mean of the three measurements was used to define blood pressure. Subjects with blood pressure greater or equal to 140/90 mm Hg and/or under current antihypertensive treatment were considered hypertensive. Normotensives were defined as untreated subjects with blood pressure less than 140/90 mm Hg. Cardiovascular risk factors were also collected at baseline and follow up. Height and weight were measured and body mass index (BMI) was calculated as weight divided by squared height $\left(\mathrm{kg} / \mathrm{m}^{2}\right)$. Overweight was defined as BMI greater or equal to 25 and lower than 30, and obesity as BMI greater or equal to 30 . Information on smoking status, alcohol consumption, and sports activities was provided by the subjects through interviews. Smokers were defined as those having smoked at least one cigarette a day, alcohol consumption was quantified in glasses per day (in men, drinkers were defined as those drinking three units per day or more, and in women as those drinking one unit per day or more), and sports activities were reported in hours per week (less than two hours per week was the limit to define non-participation in sports activities).

Additional information was collected in both incident cases and controls. Assessment of occupational hazards was made by the occupational physicians on the basis of their knowledge of the workplace and of each participant's tasks at work. Information on physical exertion at work, shift work, and job insecurity assessed by the risk of dismissal was provided by the worksite physician who answered a questionnaire. Each hazard was assessed by one single item with a dichotomous answer (yes/no). Before the medical follow up examination and therefore without knowing their blood pressure status, participants completed in person a self-administered questionnaire on working organisation modifications in the past years (restructuring, relocation or subcontracting, and downsizing), psychological demand, decision latitude and social support at work, social support outside of work, and recent stressful life events.

The self-administrated questionnaire of Karasek ${ }^{5}$ was used to measure psychological demand ( 5 items), job decision latitude (9 items), and social support at work ( 11 items). Items were coded on a 4-level scale, with 1 indicating a strong disagreement, 2 disagreement, 3 agreement, and 4 a strong agreement. Scores range from 5 to 20 for psychological demand, from 24 to 96 for decision latitude, and from 1 to 34 for social support at work. The validated French version of psychological demand and job decision latitude dimensions was used. ${ }^{19} 20$ The exposure to high psychological demand and low decision latitude was determined by dichotomising at the median score of each dimension for each sex separately. The results were classified into four exposure groups. The low strain group combined low psychological demand and high decision latitude. Job strain was defined as an exposure to high psychological demand together with low decision latitude and was considered to be the highest exposure group. Participants exposed to low decision latitude but having a low psychological demand were classified as working in passive jobs; those being exposed to a high psychological demand but having high decision latitude were classified in active jobs. Social support at work measures socio-emotional, instrumental support, and hostility from supervisors and colleagues. The score of the dimension was dichotomised to the median to define high and low social support at work.

Social support outside of work was assessed by the 23-item Social Support Questionnaire for Transactions (SSQT) validated in French. ${ }^{21}$ This scale measures two components of social support, social-emotional and instrumental support. The 23 items were summed to obtain a total score, ranging from 23 to 96 . This score was dichotomised using the median to classify subjects with high and low social support transactions. The number of recent stressful life events occurring in the past 12 months was collected by a 14 -item scale. ${ }^{22}$ The answers were dichotomised in two groups (at least one event and no event).

In participants with incomplete data for psychological demand, decision latitude, social support at work, or social support outside of work, the total score was recalculated for each questionnaire using the lowest and the highest value for each missing answer. If the worker was classified in the same category whatever the theoretical value of the missing answer(s), the score was dichotomised using the same procedure as above. If the classification was different according to the theoretical value of the missing answer(s), the total score was considered as missing. Participants with incomplete data on the stressful events questionnaire but who reported at least one event were considered as respondents to the whole questionnaire. These procedures allowed us to include 59 additional participants ( 38 men and 21 women) in multivariate analyses. As a result, 44 workers (27 men and 17 women) were excluded from the multivariate analyses because of missing data. These 59 additional participants did not modify the variables distribution.

\section{Statistical analysis}

Quantitative variables were expressed as mean (standard deviation (SD)) and Student's $t$ test was used to compare two groups for quantitative variables. Categorical variables with more than two categories were coded as dummy variables. Groups for qualitative variables were compared using a $\chi^{2}$ test, or a Fisher's exact test when appropriate. Unconditional logistic regression was used to calculate odds ratios instead of 
Table 1 Job constraints according to occupational category in normotensive and hypertensive participants

\begin{tabular}{|c|c|c|c|c|c|c|c|c|c|c|}
\hline & \multicolumn{5}{|c|}{ Normotensive participants } & \multicolumn{5}{|c|}{ Hypertensive participants } \\
\hline & Low strain & Active & Passive & Job strain & p Value & Low strain & Active & Passive & Job strain & p Value \\
\hline \multicolumn{11}{|l|}{ Men, $\mathrm{n}(\%)$} \\
\hline Executives & $9(23.1)$ & $17(43.6)$ & $8(20.5)$ & $5(12.8)$ & 0.002 & $2(9.1)$ & $16(72.7)$ & $1(4.6)$ & $3(13.6)$ & 0.003 \\
\hline Middle executives & $21(20.2)$ & $45(43.3)$ & $14(13.4)$ & $24(23.1)$ & & 5 (11.9) & $15(35.7)$ & $9(21.4)$ & $13(31.0)$ & \\
\hline Employees & 6 (19.3) & $4(12.9)$ & $11(35.5)$ & $10(32.3)$ & & $1(11.1)$ & $4(44.5)$ & $1(11.1)$ & $3(33.3)$ & \\
\hline Workers & $17(16.0)$ & $26(24.6)$ & $36(34.0)$ & $27(25.4)$ & & $5(7.8)$ & $14(21.9)$ & $24(37.5)$ & $21(32.8)$ & \\
\hline \multicolumn{11}{|l|}{ Women, n (\%) } \\
\hline Executives & $5(29.4)$ & $9(52.9)$ & $2(11.8)$ & $1(5.9)$ & 0.002 & $1(16.7)$ & $2(33.3)$ & $1(16.7)$ & $2(33.3)$ & 0.487 \\
\hline Middle executives & $6(21.4)$ & $14(50.0)$ & 3 (10.7) & $5(17.9)$ & & $3(23.1)$ & $6(46.1)$ & $2(15.4)$ & $2(15.4)$ & \\
\hline Employees & $17(29.8)$ & $8(14.1)$ & $15(26.3)$ & $17(29.8)$ & & $4(12.9)$ & $7(22.6)$ & 12 (38.7) & $8(25.8)$ & \\
\hline Workers & $3(25.0)$ & 1 (8.3) & $6(50.0)$ & $2(16.7)$ & & $1(9.1)$ & $1(9.1)$ & $6(54.5)$ & $3(27.3)$ & \\
\hline
\end{tabular}

conditional logistic regression as the variable age was matched in a large range of variation (SD 10 years). In these conditions, it has been shown that the results of conditional and unconditional analyses are roughly the same. ${ }^{23}$ The crude association between each variable of interest and incident hypertension was explored, and adjusted odds ratios were calculated controlling for potential confounders. The final multivariate model included age, educational level, behaviour (except smoking in men), and social support at work. Also, other variables with $\mathrm{p}$ values lower than 0.30 in the bivariate analysis were included in multivariate models (recent stressful life events in both men and women, low support outside of work in women). In both sexes, four models were used: (1) adjustment on age, (2) adjustment on age, educational level, and recent stressful life events, and (3) adjustment on age, stressful life events, educational level, behaviours, and in women, social support outside of work, and (4) addition of social support at work to the third model. Two-way interaction terms were tested between all the variables included in the final multivariate model. None of these interaction terms were significant. Data analysis was performed using the SAS statistical software package. ${ }^{24}$ Analysis was conducted in men and in women separately.

\section{RESULTS}

\section{Questionnaires}

For psychological demand, median scores were 13 in both men and women. For decision latitude, median scores were higher in men than in women (71 and 66 respectively).

Table 2 Characteristics of hypertensive cases compared with normotensive participants

\begin{tabular}{|c|c|c|c|c|c|c|}
\hline & \multicolumn{3}{|l|}{ Men } & \multicolumn{3}{|l|}{ Women } \\
\hline & $\begin{array}{l}\text { Hypertensive } \\
\text { ( } n=142 \text { ) }\end{array}$ & $\begin{array}{l}\text { Normotensive } \\
(n=284)\end{array}$ & p Value & $\begin{array}{l}\text { Hypertensive } \\
(n=61)\end{array}$ & $\begin{array}{l}\text { Normotensive } \\
(n=122)\end{array}$ & p Value \\
\hline Body mass index $\left(\mathrm{kg} / \mathrm{m}^{2}\right)(\mathrm{SD})$ & $26.9(3.5)$ & $25.0(3.1)$ & $<0.0001$ & $26.1(5.1)$ & $23.5(3.6)$ & 0.001 \\
\hline $\mathrm{BMl}<25 \mathrm{~kg} / \mathrm{m}^{2}, \mathrm{n}(\%)$ & $39(27.5)$ & $154(54.3)$ & $<0.0001$ & $29(47.6)$ & $85(69.7)$ & 0.001 \\
\hline $30 \mathrm{~kg} / \mathrm{m}^{2}>\mathrm{BMl} \geqslant 25 \mathrm{~kg} / \mathrm{m}^{2}$ & $79(55.6)$ & $110(38.7)$ & & $21(34.4)$ & $32(26.2)$ & \\
\hline $\mathrm{BMI} \geqslant 30 \mathrm{~kg} / \mathrm{m}^{2}$ & $24(16.9)$ & $20(7.0)$ & & $11(18.0)$ & $5(4.1)$ & \\
\hline Smokers ( $\geqslant 1$ cig/day), $n(\%)$ & $47(33.1)$ & $105(37.0)$ & 0.431 & 21 (34.3) & $29(23.8)$ & 0.127 \\
\hline Alcohol*, n (\%) & $24(16.9)$ & $35(12.3)$ & 0.197 & $12(19.7)$ & $11(9.0)$ & 0.040 \\
\hline Physical inactivity†, n (\%) & 77 (54.2) & $167(58.8)$ & 0.368 & 48 (78.7) & 91 (74.6) & 0.511 \\
\hline \multicolumn{7}{|l|}{ Occupation, $\mathrm{n}(\%)$} \\
\hline Executives & $22(15.5)$ & $39(13.7)$ & 0.166 & $6(9.9)$ & $17(13.9)$ & 0.352 \\
\hline Middle executives & 45 (31.7) & $107(37.7)$ & & $13(21.3)$ & $33(27.1)$ & \\
\hline Employees & $9(6.3)$ & $31(10.9)$ & & $31(50.8)$ & $60(49.2)$ & \\
\hline Workers & $66(46.5)$ & $107(37.7)$ & & $11(18.0)$ & $12(9.8)$ & \\
\hline \multicolumn{7}{|l|}{ Educational level, n (\%) } \\
\hline$\geqslant 12$ years & $22(15.5)$ & 53 (18.7) & 0.216 & $2(3.3)$ & $24(19.7)$ & 0.009 \\
\hline $7-11$ years & $108(76.1)$ & $194(68.3)$ & & $42(68.8)$ & $74(60.6)$ & \\
\hline$\leqslant 6$ years & $12(8.4)$ & $37(13.0)$ & & 17 (27.9) & 24 (19.7) & \\
\hline \multicolumn{7}{|l|}{ Occupational hazards, n (\%) } \\
\hline Physical exertion & $80 / 139(57.5)$ & $154 / 268(57.5)$ & 0.986 & $19 / 60$ (31.7) & $31 / 118(26.3)$ & 0.449 \\
\hline Shift work & $38 / 142(26.8)$ & $76 / 284(26.8)$ & 1.000 & $5 / 61(8.2)$ & $11 / 121(9.1)$ & 0.841 \\
\hline Job insecurity & $14 / 140(10.0)$ & $30 / 276(10.9)$ & 0.785 & $8 / 60(13.3)$ & $21 / 119(17.6)$ & 0.460 \\
\hline \multicolumn{7}{|l|}{ Organisational changes, $\mathrm{n}(\%)$} \\
\hline Restructuring & $87 / 141$ (61.7) & $177 / 282$ (62.8) & 0.831 & $32 / 61(52.5)$ & $81 / 120(67.5)$ & 0.048 \\
\hline Relocation & $70 / 138(50.7)$ & $157 / 280(56.1)$ & 0.302 & $15 / 60(25.0)$ & $35 / 117(29.9)$ & 0.492 \\
\hline Downsizing & $82 / 137$ (59.8) & $167 / 278(60.1)$ & 0.966 & $26 / 60(43.3)$ & $58 / 119(48.7)$ & 0.494 \\
\hline Job strain, $\mathrm{n}(\%)$ & $\mathrm{n}=137$ & $\mathrm{n}=280$ & & $\mathrm{n}=61$ & $\mathrm{n}=114$ & \\
\hline $\mathrm{PD}+, \mathrm{DL}-($ job strain) & $40(29.2)$ & $66(23.6)$ & 0.086 & $15(24.6)$ & $25(21.9)$ & 0.182 \\
\hline $\mathrm{PD}-, \mathrm{DL}-$ (passive) & $35(25.5)$ & $69(24.6)$ & & $21(34.4)$ & $26(22.8)$ & \\
\hline $\mathrm{PD}+, \mathrm{DL}+$ (active) & 49 (35.8) & 92 (32.9) & & $16(26.2)$ & $32(28.1)$ & \\
\hline PD -, DL + (low strain) & $13(9.5)$ & $53(18.9)$ & & $9(14.8)$ & $31(27.2)$ & \\
\hline Low support at work, n (\%) & $73 / 133$ (54.9) & $142 / 281(50.5)$ & 0.407 & $34 / 56(60.7)$ & $59 / 115(51.3)$ & 0.246 \\
\hline Low support out of work, $n(\%)$ & $81 / 141(57.4)$ & $150 / 280(53.6)$ & 0.451 & $38 / 61(62.3)$ & $53 / 121(43.8)$ & 0.018 \\
\hline Stressful life events, n (\%) & $106 / 137(77.4)$ & $247 / 280(88.2)$ & 0.004 & $45 / 60(75.0)$ & $108 / 122(88.5)$ & 0.019 \\
\hline
\end{tabular}

$\mathrm{SD}$, standard deviation; PD, psychological demand; $\mathrm{DL}$, decision latitude; + , high level; -, low level.

*Men, three glasses or more per day; women, one glass or more per day.

†Less than two hours per week. 
Median scores were similar in both sexes for social support at and outside of work (21 and 49 respectively).

\section{Description of the population}

A total of 203 cases (142 men and 61 women) and 406 controls (284 men and 122 women) were included in the study. Mean age was 41.8 (SD 7.8) years and 43.5 (SD 7.5) years in men and in women respectively. Blood pressure was higher in the whole sample of men than in the sample of women (128.0 (SD 12.2)/81.4 (SD 8.2) mm Hg $v 125.0$ (SD 16.3)/79.1 (SD 9.9) mm Hg). BMI was also higher in men than in women $(25.6$ (SD 3.4) $v 24.4$ (SD 4.3)).

\section{Job constraints and demographic characteristics}

Table 1 shows the association between job constraints and occupational categories separately in normotensive and hypertensive participants.

In normotensive men, executive and middle executive occupations were predominantly classified in active jobs whereas employees and workers were mostly in the passive jobs category. In hypertensive men, workers were predominantly classified in the passive group while the other occupational groups were mostly in the active jobs category.

In normotensive women, executives and middle executives were mostly classified in active jobs and workers were predominantly classified in the passive group. Normotensive women who were employees were predominantly classified in the low exposure and job strain groups. In hypertensive women, no significant difference was observed for job constraints distribution according to occupational categories.

In both normotensive and hypertensive men and women, mean age was not significantly different between job constraints categories (data not shown).

\section{Comparison between incident hypertensives and controls}

In both sexes, mean BMI was higher in incident hypertensive subjects compared with normotensive. Percentages of overweight and obesity were higher in hypertensive men and women compared to normotensive participants. In hypertensive women, alcohol consumption was higher and educational level lower than in normotensive $(p=0.040$ and 0.009 respectively). Prevalence of restructuring in the past years was lower in hypertensive women than in normotensive $(p=0.048)$ (table 2$)$. However, this factor was no longer significant after adjusting for the factors included in the final multivariate model.

Although the percentage of hypertensive men exposed to job strain was higher compared with normotensive, the difference was not significant. The percentage of hypertensive women exposed to passive jobs was higher compared with normotensive women but the difference was not significant. Although prevalence of low social support at work was higher in hypertensive men and women, the difference was not significant compared with normotensive. Social support outside of work was significantly lower in hypertensive women, compared with controls. Hypertensive men and women reported fewer recent stressful life events than controls (table 2).

Table 3 shows the final multivariate logistic regression model in each sex. In women, passive and active jobs were strongly related to hypertension. Recent stressful life events were found to be negatively related to hypertension. Lower educational level remained significant in the final model. Obesity and alcohol consumption were significant risk factors for hypertension. Social support at work was not related to hypertension, nor did it moderate the relation of job constraints with hypertension. In men, after controlling for potential confounders, each of the combinations of psychological demand with decision latitude was significantly related to hypertension. Job strain had the highest association with hypertension compared with active and passive jobs. Overweight and obesity were significantly associated with hypertension and participants having experienced stressful life events were found to be less at risk of hypertension. Adding social support at work in the model did not decrease significantly the relation between job constraints and hypertension.

In both sexes, the interaction between job constraints and social support at work was not significant $(p=0.669$ and $\mathrm{p}=0.679$ in women and men respectively). In women with high support at work, odds ratios were 1.35 (95\% CI 0.09 to 20.03) for job strain, 10.56 (95\% CI 1.43 to 77.95 ) for passive jobs, and 12.66 (95\% CI 1.46 to 109.50 ) for active jobs whereas in women with low support at work odds ratios were 2.05 (95\% CI 0.33 to 12.84 ), 2.57 (95\% CI 0.39 to 16.92 ), and 2.77 (95\% CI 0.39 to 19.85 ) for job strain, passive jobs and active jobs respectively. In men with high support at work,

Table 3 Psychosocial and cardiovascular risk factors and hypertension in women and in men: multivariate analysis (odds ratios)

\begin{tabular}{|c|c|c|}
\hline & Men $(n=399)$ OR $(95 \% \mathrm{Cl})$ & Women $(n=166)$ OR $(95 \% \mathrm{Cl})$ \\
\hline \multicolumn{3}{|l|}{ Job constraints } \\
\hline $\mathrm{PD}+, \mathrm{DL}-($ job strain) & $2.60(1.15$ to 5.85$)$ & $3.20(0.92$ to 11.12$)$ \\
\hline PD -, DL - (passive) & $2.30(1.01$ to 5.26$)$ & 4.73 (1.36 to 16.42$)$ \\
\hline $\begin{array}{l}\mathrm{PD}+, \mathrm{DL}+\text { (active) } \\
\mathrm{PD}-, \mathrm{DL}+\text { (low strain) }\end{array}$ & $\begin{array}{l}2.39(1.10 \text { to } 5.18) \\
1.00\end{array}$ & $\begin{array}{l}4.51 \text { (1.24 to } 16.43) \\
1.00\end{array}$ \\
\hline Low social support at work & 1.31 (0.80 to 2.12$)$ & $0.62(0.27$ to 1.41$)$ \\
\hline Age & 1.00 (0.97 to 1.04$)$ & 0.98 (0.93 to 1.04 ) \\
\hline \multicolumn{3}{|l|}{ Educational level } \\
\hline$\leqslant 6$ years & $0.53(0.20$ to 1.39$)$ & 8.12 (1.30 to 50.73$)$ \\
\hline $7-11$ years & $1.24(0.67$ to 2.30$)$ & $5.47(1.05$ to 28.41$)$ \\
\hline$\geqslant 12$ years & 1.00 & 1.00 \\
\hline Obesity $\left(B M I \geqslant 30 \mathrm{~kg} / \mathrm{m}^{2}\right)$ & 6.54 (2.99 to 14.29 ) & 13.20 (3.34 to 52.14$)$ \\
\hline Overweight $(25 \leqslant \mathrm{BMI}<30)$ & 3.47 (2.09 to 5.79$)$ & $1.19(0.50$ to 2.87$)$ \\
\hline $\mathrm{BMI}<25 \mathrm{~kg} / \mathrm{m}^{2}$ ) & 1.00 & 1.00 \\
\hline Alcohol consumption* & $1.85(0.96$ to 3.55$)$ & $3.47(1.18$ to 10.25$)$ \\
\hline Smoking ( $\geqslant 1$ cigarette/day) & - & $1.98(0.84$ to 4.67$)$ \\
\hline Physical inactivity ( $<2 \mathrm{~h} /$ week) & $0.74(0.46$ to 1.20$)$ & $1.10(0.44$ to 2.75$)$ \\
\hline Stressful life event & $0.37(0.20$ to 0.67$)$ & $0.32(0.12$ to 0.89$)$ \\
\hline Low support outside of work & - & $1.98(0.87$ to 4.54$)$ \\
\hline
\end{tabular}


odds ratios were 4.03 (95\% CI 1.06 to 15.24), 4.23 (95\% CI 1.09 to 16.33 ), and 4.12 (95\% CI 1.27 to 13.35 ) for job strain, passive and active jobs respectively, and in men with low support at work, odds ratios were 2.04 (95\% CI 0.67 to 6.25 ) for job strain, 1.65 (95\% CI 0.52 to 5.24 ) for passive jobs, and 1.65 (95\% CI 0.52 to 5.30 ) for active jobs.

\section{DISCUSSION}

In this population of working men and women, we found in both sexes an association between job constraints and hypertension. Our results confirm the role of job constraints as hypertension risk factors, particularly in women. In men, each of the combinations of psychological demand with decision latitude was significantly related to hypertension. Job strain had the highest association with hypertension, compared with active and passive jobs. The relations between passive jobs and hypertension and active jobs and hypertension were at least nearly two times stronger in women than in men. The strength of the association was higher for each job constraint compared to men. However, the association with job strain was not significant in women.

In both sexes, low social support at work was not significantly associated to hypertension and did not buffer the effect of organisational risk factors.

In both sexes, obesity was a risk factor for hypertension. Stressful life events were negatively related to hypertension in both sexes (that is, men and women reporting stressful life events were less at risk of hypertension). Alcohol consumption was significantly related to hypertension in women only.

Our study has several strengths. Firstly, we administrated the 25-item three dimension Job Content Questionnaire including the more recently added social support dimension. ${ }^{6}$ The questionnaire was designed to minimise self-report bias in responses. Previous research showed that the variance for decision latitude is mostly interoccupational, indicating that subjects are able to evaluate their jobs objectively. However, much of the variance in psychological demand is intraoccupational, suggesting a strong subjective component, ${ }^{525}$ We also had an assessment of physical demands and job insecurity reported by occupational physicians.

Secondly, a bias in self-reports has been previously reported in subjects aware of their blood pressure status. ${ }^{26}$ In our study, all participants were hypertension free one year before the inclusion (baseline screening). Furthermore, only 20 incident hypertensive subjects ( 13 men and 7 women) had been informed of a high blood pressure level at least at one occasion before their inclusion in the case control study. Conversely, only two normotensive men at baseline and at follow up were informed of a high blood pressure level at least once before their inclusion. We do therefore think that such a bias does not account for the results in our study.

Thirdly, a major strength of our study is the use of a definition of hypertension including three standardised blood pressure measurements and the use of an automatic device. Blood pressure measurement is subject to random fluctuations, caused by either the process of measurement itself or temporary deviation from usual BP levels. The proportion of true high blood pressure measurements has been shown to be lower in younger and higher in older age groups. ${ }^{27}$ Using the mean of three measurements may reduce the risk of classifying as hypertensive people whose usual blood pressure is lower than screening blood pressure.

This study may also be subject to limitations. A healthy worker effect has to be taken into account in this working population. Workers exposed to a high level of job constraints could have left their employment to work in a lower strain job, leading to underestimate the actual relation. Also older workers are likely to be in jobs with higher decision latitude and thus with lower job strain. ${ }^{25}$ However this bias was minimised, including workers who were normotensive one year before the study and being in the same job for at least one year. This study was designed to take into account most of the potential confounders to isolate the effect of organisational constraints. Nevertheless, we did not assess personality traits. They are supposed to influence coping strategies facing one's work related strain. ${ }^{28}$ However, they can lead to an overadjustment, coping behaviours being in turn partly influenced by exposure.

In men, we found a significant relation between all job constraints and hypertension. The highest association was observed with job strain. These results are consistent with the assumption of the model that the combination of high psychological demand and low control results in the more adverse health outcomes. To our knowledge, only one previous case control study was carried out in men. ${ }^{11}$ Job strain versus other groups was significantly associated with increased workplace diastolic blood pressure. Our own findings were consistent with these results, showing a higher and significant risk of hypertension in men exposed to job strain compared with the low strain group. However, passive and active jobs were also significantly associated with hypertension. Active work situations are characterised by autonomy and thus fewer stress reactions. In our sample of men, their association with hypertension was as high as the relation of passive jobs with hypertension. Previous cross sectional studies using casual blood pressure measurement reported inconsistent results. In men, a significant positive effect of job strain on casual blood pressure was found for systolic $^{29}$ and diastolic blood pressure. ${ }^{30}$ An association between a low decision latitude and systolic blood pressure was reported. 293132

As shown in previous studies, ${ }^{50}$ psychological demand medians were similar in men and in women but decision latitude median scores were lower in women than in men. Thus in our sample, psychological demand and decision latitude were dichotomised using sex specific median scores. The procedure resulted in $25.4 \%$ of men and $22.9 \%$ of women being classified as exposed to high job strain. Previous studies that used the same cut point for both sexes to dichotomise the two dimensions reported a higher prevalence of job strain in women than in men. ${ }^{19}{ }^{33}$ Other authors chose cut-off scores in order to separate the $20 \%$ of subjects with the highest strain. ${ }^{11}$ According to thresholds used, subjects' classification may differ and lead to different results. No consensual strategy was defined to avoid misclassification and determine threshold effect.

We observed a higher association between job constraints and hypertension in women than men. Several explanations can be suggested. Differences between men and women may be partly explained by sex differences in work characteristics. Men and women seem to be confined to working in jobs that are highly sex segregated. In our sample, women worked predominantly in clerical jobs whereas men were mostly concentrated in middle executive and workers occupations. ${ }^{15}$ Eighty per cent of the workforce is employed in occupations dominated by the same sex. Even when men and women perform the same type of work, women have less control over their work than do men. Thus, exposure to occupational hazards including work stress related factors might differ between sexes. Other occupational exposures relevant to women may also not be captured by the demand-control model, which was originally designed and tested in men. ${ }^{34}$ Other stressful situations outside of work may influence blood pressure levels. Working women are more likely to be exposed to both work and home demands. The combination of high job strain with large family responsibilities was reported to have a greater effect on blood pressure than the exposure to either one of these factors. ${ }^{35}$ 
Our study reports the first results of a case control design in women. Fewer studies on job strain and blood pressure were conducted in women compared with men. Only one report found a significant effect of job strain on blood pressure in women. However, the association between decision latitude and blood pressure was the opposite from what was expected. ${ }^{36}$

We did not find a main effect of social support at work on hypertension in our sample of men and women. Neither did social support at work buffer the effect of job strain on hypertension. Although a lack of power in our study has to be kept in mind to explain this result, previous studies failed also to show a significant relation between blood pressure levels during workday and social support at work. ${ }^{13} 143738$ Conversely, one study showed a main effect of support at work depending on the source of support and sex (that is, positive effect of supervisor support for women and of coworker support for men). ${ }^{39}$ Social support has been mainly studied in relation to cardiovascular disease. There is strong and consistent evidence that social isolation and lack of social support at and outside of work are independent risk factors for coronary heart disease onset and prognosis. ${ }^{40}{ }^{41}$ In our sample of women, we found a high although non-significant relation between low support outside of work and hypertension. It was suggested that women react to stressful circumstances by joining social groups to reduce their vulnerability. ${ }^{42}$ Lack of support outside of work may then have a direct effect on blood pressure levels.

In addition to job constraints, obesity was related to hypertension in both sexes. This finding is consistent with previous reports. ${ }^{43}{ }^{44}$ In our study, alcohol consumption was a significant risk factor for hypertension in women only. These results may suggest that our sample of women is at risk of hypertension even for a low level of alcohol consumption. The relation between alcohol consumption and hypertension has been established in both sexes. ${ }^{45}$ However, the nature of this association is not clearly defined. Some authors reported a linear relation ${ }^{46}$ whereas others described a $\mathrm{J}$ shaped relation. ${ }^{45}$ Other characteristics of alcohol consumption might also be taken into account, such as type of beverage and drinking patterns. Lack of sports activity was not significantly related to hypertension in our sample. These results can be partly due to the fact that we assessed physical activity according to its length rather than to its intensity. A significant relation between physical activity intensity and incident hypertension has been previously described. However, this relation has been found in men but not in women. ${ }^{478}$

Hypertensive participants declared fewer recent stressful life events than normotensives. A previous study also showed that hypertensives were less likely to report stressful life events than normotensives. ${ }^{49}$ This may be explained by a repressive coping in individuals who paradoxically manifest high levels of physiological arousal. ${ }^{50}$ Another mechanism may lead hypertensives exposed to chronic stressors to become less sensitive to acute stressors and to perceive them as less threatening. ${ }^{3}$

Our study provides support for a relation between job constraints and incident hypertension in both sexes. However, a stronger association was observed in women compared with men. The relation of each job constraint with hypertension was higher in women compared with men. The association of passive and active jobs and hypertension was at least twice in women than in men. These results suggest that not only the combination of high demand and low control but also the two other combinations of job constraints (namely active and passive jobs) seem to be harmful in both sexes at least at the same magnitude. These findings emphasise the need of addressing more sex specific concepts of work related stress in one hand, and to understand the direct and indirect mechanisms linking psychosocial factors and hypertension in both sexes on the other hand.

\section{ACKNOWLEDGEMENTS}

This study was undertaken under the auspices of the French Society of Hypertension and its epidemiology group. The following pharmaceutical companies have supported the activity of the group and this study: Astra, Bristol-Myers-Squibb, Debat Cardio, Hoeschst-Houde, Information Servier, Lipha, Merck Sharp \& Dohme Chibret, Roussel, Rhône Poulenc Rorer, Wyeth-Lederle, Zeneca, GlaxoWelcome. We thank the staff of the worksites without whom this work would not have been possible.

\section{Authors' affiliations}

S Radi, T Lang, V Lauwers-Cancès, E Diène, Département d'Epidémiologie et de Santé Publique, Unité INSERM 558 and IFR 126, Faculté de Médecine, Toulouse, France

G Chatellier, Département d'Informatique Hospitalière, Hôpital Européen Georges Pompidou, Paris, France

L Larabi, R De Gaudemaris, Service de Médecine et Santé au Travail, $\mathrm{CHU}$ de Grenoble, Grenoble, France

Samia Radi was supported by a combined grant from the French Society of Hypertension and Sanofi-Synthélabo and by a combined grant from the Ministère des Affaires Sociales, du Travail et de la Solidarité, and the Institut de Veille Sanitaire.

Conflicts of interest: none.

\section{REFERENCES}

1 European Foundation for the Improvement of Living and Working Conditions. Time constraints and autonomy at work in the European Union, 1997. Available at http://www.eurofound.ie/publications/files/ EF9743EN.pdf (accessed 9 June 2005).

2 Pickering TG, Devereux RB, James GD, et al. Environmental influences on blood pressure and the role of job strain. J Hypertens Suppl 1996; 14:S179-85.

3 Nyklicek I, Vingerhoets JJ, Van Heck GL. Hypertension and objective and selfreported stressor exposure: a review. J Psychosom Res 1996;40:585-601.

4 Karasek RA. Job demands, job decision latitude, and mental strain: implications for jobs redesign. Adm Sci Q 1979;24:285-308.

5 Karasek R, Brisson C, Kawakami N, et al. The Job Content Questionnaire (JCQ): an instrument for internationally comparative assessments of psychosocial job characteristics. J Occup Health Psychol 1998;3:22-55.

6 Johnson JV, Hall EM. Job strain, work place social support, and cardiovascular disease: a cross-sectional study of a random sample of the Swedish working population. Am J Public Health 1988;78:1336-42.

7 Belkic KL, Landsbergis PA, Schnall PL, et al. Is job strain a major source of cardiovascular disease risk? Scand J Work Environ Health 2004;30:85-128.

8 Kuper H, Marmot M. Job strain, job demands, decision latitude, and risk of coronary heart disease within the Whitehall II study. J Epidemiol Community Health 2003;57:147-53

9 Schnall PL, Landsbergis PA, Baker D. Job strain and cardiovascular disease. Annu Rev Public Health 1994; 15:381-411.

10 Hellerstedt WL, Jeffery RW. The association of job strain and health behaviours in men and women. Int J Epidemiol 1997;26:575-83.

11 Schnall PL, Pieper C, Schwartz JE, et al. The relationship between 'job strain', workplace diastolic blood pressure, and left ventricular mass index. Results of a case-control study. JAMA 1990;263:1929-35.

12 Schnall PL, Landsbergis PA, Pickering TG, et al. Perceived job stress, job strain, and hypertension. Am J Public Health 1994;84:320-1.

13 Landsbergis PA, Schnall PL, Warren K, et al. Association between ambulatory blood pressure and alternative formulations of job strain. Scand J Work Environ Health 1994;20:349-63.

14 Steptoe A, Lundwall K, Cropley M. Gender, family structure and cardiovascular activity during the working day and evening. Soc Sci Med 2000;50:531-9.

15 Lang T, De Gaudemaris R, Chatellier G, et al. Prevalence and therapeutic control of hypertension in 30,000 subjects in the workplace. Hypertension 2001;38:449-54

16 De Gaudemaris R, Lang T, Chatellier G, et al. Socioeconomic inequalities in hypertension prevalence and care: the IHPAF Study. Hypertension 2002;39:1119-25.

17 Radi S, Lang T, Lauwers-Cances V, et al. One-year hypertension incidence and its predictors in a working population: the IHPAF study. J Hum Hypertens 2004; 18:487-94

18 O'Brien E, Mee F, Atkin N, et al. Evaluation of three devices for selfmeasurement of blood pressure according to the revised British Hypertension Society Protocol: the Omron HEM-705CP, Philips HP5332, and Nissei DS175. Blood Press Monit 1996;1:55-61.

19 Larocque B, Brisson C, Blanchette C. Cohérence interne, validité factorielle et validité discriminante de la traduction française des échelles de demande 
psychologique et de latitude décisionnelle du "Job Contnet Questionnaire" de Karasek. Rev Epidemiol Sante Publique 1998;46:371-81.

20 Niedhammer I. Psychometric properties of the French version of the Karasek Job Content Questionnaire: a study of the scales of decision latitude, psychological demands, social support, and physical demands in the GAZEL cohort. Int Arch Occup Environ Health 2002;75:129-44.

21 Suurmeijer TP, Doeglas DM, Briancon S, et al. The measurement of social support in the 'European Research on Incapacitating Diseases and Social Support': the development of the Social Support Questionnaire for Transactions (SSQT). Soc Sci Med 1995;40:1221-9.

22 Niedhammer I, Goldberg M, Leclerc A, et al. Psychosocial factors at work and subsequent depressive symptoms in the Gazel cohort. Scand J Work Environ Health 1998;24:197-205.

23 Breslow NE, Day NE. Statistical methods in cancer research. Volume 1: the analysis of case-control studies. Lyon: WHO, 1980.

24 SAS/STAT User's Guide, Version 8.2. Cary, NC: SAS Institute Inc: 19992001.

25 Schwartz JE, Pieper CF, Karasek RA. A procedure for linking psychosocial job characteristics data to health surveys. Am J Public Health 1988;78:904-9.

26 Tennant C. Life stress and hypertension. J Cardiovasc Risk 2001;8:51-6.

27 Marshall T. When measurements are misleading: modelling the effects of blood pressure misclassification in the English population. $B M$ 2004:328:933.

28 Neboit M, Vezina M. Stress au travail et sante psychique. Toulouse: Octares Editions, 2002

29 Cesana G, Sega R, Ferrario M, et al. Job strain and blood pressure in employed men and women: a pooled analysis of four northern Italian population samples. Psychosom Med 2003:65:558-63.

30 Su CT, Yang HJ, Lin CF, et al. Arterial blood pressure and blood lipids as cardiovascular risk factors and occupational stress in Taiwan. Int J Cardiol 2001;81:181-7.

31 Pieper C, LaCroix AZ, Karasek RA. The relation of psychosocial dimensions of work with coronary heart disease risk factors: a meta-analysis of five United States data bases. Am J Epidemiol 1989;129:483-94.

32 Matthews KA, Cottington EM, Talbott E, et al. Stressful work conditions and diastolic blood pressure among blue collar factory workers. Am J Epidemio 1987; 126:280-91.

33 Bosma H, Peter R, Siegrist J, et al. Two alternative job stress models and the risk of coronary heart disease. Am J Public Health 1998;88:68-74.

34 Johnson JV, Hall EM. Dialectic between conceptual and causal inquiry in psychosocial work-environment research. J Occup Health Psychol 1996;1:362-74.

35 Brisson C, Laflamme N, Moisan J, et al. Effect of family responsibilities and job strain on ambulatory blood pressure among white-collar women. Psychosom Med 1999;61:205-13.
36 Greenlund KJ, Liu K, Knox S, et al. Psychological work characteristics and cardiovascular disease risk factors in young adults: the Cardia study. Soc Sci Med 1995:41:717-23.

37 Kawakami N, Haratani T, Araki S. Job strain and arterial blood pressure, serum cholesterol, and smoking as risk factors for coronary heart disease in Japan. Int Arch Occup Environ Health 1998;71:429-32.

38 Jonsson D, Rosengren A, Dotevall A, et al. Job control, job demands and social support at work in relation to cardiovascular risk factors in MONICA 1995, Göteborg. J Cardiovasc Risk 1999;6:379-85.

39 Karlin WA, Brondolo E, Schwartz J. Workplace social support and ambulatory cardiovascular activity in New York city traffic agents. Psychosom Med 2003;65:167-76.

40 Hemingway $\mathbf{H}$, Marmot $M$. Evidence based cardiology: psychosocial factors in the aetiology and prognosis of coronary heart disease. Systematic review of prospective cohort studies. BMJ 1999;318:1460-7.

41 Bunker SJ, Colquhoun DM, Esler MD, et al. "Stress" and coronary heart disease: psychosocial risk factors. Med J Aust 2003;178:272-6.

42 Taylor SE, Klein LC, Lewis BP, et al. Biobehavioral responses to stress in females: tend-and-befriend, not fight-or-flight. Psychol Rev 2000;107:41 1-29.

43 Chobanian AV, Bakris GL, Black HR, et al. The Seventh Report of the Joint National Committee on prevention, detection, evaluation, and treatment of high blood pressure. JAMA 2003;289:2560-72.

44 Whelton PK, He J, Appel $\amalg$, et al. Primary prevention of hypertension. Clinical and public health advisory from the National High Blood Pressure Education Program. JAMA 2002;288:1882-8.

45 Marmot MG, Elliott P, Shipley MJ, et al. Alcohol and blood pressure: the INTERSALT study. BMJ 1994;308:1263-7.

46 Lang T, Degoulet $\mathrm{P}$, Aime F, et al. Relationship between alcohol consumption and hypertension prevalence and control in a French population. J Chronic Dis 1987;40:713-20.

47 Haapanen N, Miilunpalo S, Vuori I, et al. Association of leisure time physical activity with the risk of coronary heart disease, hypertension and diabetes in middle-aged men and women. Int J Epidemiol 1997;26:739-47.

48 Pereira MA, Folsom AR, McGovern PG, et al. Physical activity and incident hypertension in black and white adults: the Atherosclerosis Risk in Communities Study. Prev Med 1999;28:304-12.

49 Winkleby MA, Ragland DR, Syme SL. Self-reported stressors and hypertension: evidence of an inverse association. Am J Epidemiol 1988; 127:124-34.

50 Melamed S, Ben-Avi I, Luz J, et al. Repetitive work, work underload and coronary heart disease risk factors among blue-collar workers - the CORDIS study. Cardiovascular Occupational Risk Factors Determination in Israel. J Psychosom Res 1995;39:19-29. 